\title{
T2 Mapping Sequence in the Assessment of Articular Cartilage of Knee Joint. Is There Added Value?
}

\author{
MOHAMED A. YOUSSEF, M.D.* and USAMA M. ABDELWAHAB, M.D.** \\ The Departments of Radiodiagnosis* and Orthopedic Surgery **, Faculty of Medicine, Tanta University
}

\begin{abstract}
Background: The diagnosis of early degeneration in the knee cartilage in the patients underwent routine Magnetic Resonance Imaging (MRI) is of clinical significant. T2 mapping of the knee hyaline cartilage is a rapid technique for quantitative and qualitative detection of the cartilage. T2 mapping of the cartilage is a quantitative procedure that provides informative color mapping and quantitative detection of the cartilage as morphology, water distribution and collagen fiber volume.
\end{abstract}

Aim of Study: Was assessing the value of adding T2 mapping sequence to a routine MRI of the knee to evaluate articular cartilage of the knee joint.

Patients and Methods: 50 patients with history of osteoarthritis or knee injuries ( 28 males and 22 females) with age between 15-66 years (average age, 40.9 years) were included in our study underwent MRI of the knee joint to assess the ability of T2 mapping sequence in evaluation of the knee joint articular cartilage.

Results: In this study we found that nine cases of increased $\mathrm{T} 2$ relaxation time corresponding to normal-appearing cartilage diagnosed by routine MRI. In this study, all lesions that were visible on routine knee MRI were diagnosed by T2 mapping, and some $\mathrm{T} 2$ lesions were not detected on the routine knee MRI.

Conclusion: When T2 mapping sequence was added to the routine MRI of the knee the sensitivity for detecting knee cartilage lesions was increased, especially in the detection of early cartilage degeneration.

Key Words: MRI - T2 mapping - Knee joint.

\section{Introduction}

OSTEOARTHRITIS of the knee joint is the main cause of disability and manifested by articular cartilage degeneration. The pathology may be due to acute trauma or sequel of degeneration $[\mathbf{1 , 2}]$.

Correspondence to: Dr. Mohamed A. Youssef,

The Department of Radiodiagnosis, Faculty of Medicine, Tanta University
The diagnosis of early degeneration in the knee cartilage in the patients underwent routine Magnetic Resonance Imaging (MRI) is of clinical significant. T2 mapping of the knee cartilage is a rapid procedure for quantitative and qualitative detection of the cartilage. T2 mapping of the cartilage is a quantitative procedure that provides informative color mapping and quantitative detection of the cartilage as morphology, water distribution and collagen fiber volume [3,4]

The articular cartilage can be assessed by many imaging methods. Plain X-ray was used to detect obvious damage of the cartilage, as loss of joint space [5], but not image the cartilage directly. Changes such as subchondral osteophytes can be seen, but plain X-ray is insensitive to early damage of the cartilage. Arthrography is invasive technique and provides limited information about surface of the cartilage [6].

MRI is the imaging modality of choice for the assessment of knee articular cartilage due to high contrast of soft-tissue. Imaging of the hyaline cartilage damage provide morphological information, such as cartilage defect and fissuring $[7,8]$.

Assessment of the hyaline cartilage in patients performed routine MRI of the knee joint was used sequences that assess morphology of the cartilage [9]. The relative low sensitivity in early cartilage degeneration detection is considered main limitation of cartilage imaging sequences [10]. Cartilage imaging sequences such as T2 mapping were used to assess the knee hyaline cartilage [11]

\footnotetext{
Abbreviations:

MRI : Magnetic Resonance Imaging.

T2 : Time relaxation.

O.A. : Osteoartheritis.

$\mathrm{T}$ : Tesla.
} 


\section{Aim of the work:}

The aim of this research was to assess the value of adding T2 mapping sequence to a routine knee MRI to evaluate the articular cartilage.

\section{Patients and Methods}

Between June 2017 to May 2019, 50 patients with history of osteoarthritis or knee injuries ( 28 males and 22 females) with age between 15-66 years (average age, 40.9 years) were included in this prospective study referred from Orthopedic Department to Radiodiagnosis Department of Tanta University Hospital.

Inclusion criteria: Patients with history of osteoarthritis or knee injury were included in this study.

Exclusion criteria: Patients with metallic implants and those with known cardiac pacemaker and claustrophobic patients were excluded from this study.

Approval of Research Ethics Committee and informed written consent from all cases before any technique was mandatory. All patients were imaged in GE Signa 1.5 tesla scanner using routine protocols of the knee joint (proton-density-weighted axial and sagittal, T2-weighted sagittal and coronal, and T1-weighted coronal series) with added sequence $\mathrm{T} 2$ relaxation time to determine the patellar, tibial and femoral cartilage morphological changes.

\section{Image analysis:}

MRI and T2 maps of the knee articular cartilage were evaluated for any lesions. The lesions were evaluated for their width and depth (one third, two thirds, full thickness of the cartilage thickness), and the value of T2 (20-40 millisecond, 40-60 millisecond, or 60-80 millisecond) based on visual evaluation.

\section{Statistical analysis:}

Data were collected and entered to the computer using SPSS (Statistical Package for Social Science) program for statistical analysis. $p$ (probability) value was considered to be of statistical significance if it is less than 0.05. Accuracy was represented using the terms sensitivity, specificity, positive predictive value, negative predictive value and overall accuracy. Arthroscopy was used as the standard of reference.

\section{Results}

In this study, 50 patients with history of osteoarthritis or knee injuries (28 males and 22 females) aged 15-66 years (average age, 40.9 years) were included in this study as shown in (Table 1).

Table (1): Distribution of the patients according to the demographic data.

\begin{tabular}{lcccc}
\hline \multirow{2}{*}{$\begin{array}{l}\text { Age in } \\
\text { years }\end{array}$} & \multicolumn{2}{c}{ Gender } & Number & $\%$ \\
\cline { 2 - 3 } & Male & Female & & \\
\hline $10-20$ & 2 & 1 & 3 & 6 \\
$>20-30$ & 8 & 2 & 10 & 20 \\
$>30-40$ & 2 & 2 & 4 & 8 \\
$>40-50$ & 3 & 5 & 8 & 16 \\
$>50-60$ & 7 & 7 & 14 & 28 \\
$>60-70$ & 6 & 5 & 11 & 22 \\
\hline Total & 28 & 22 & 50 & 100 \\
\hline
\end{tabular}

The patients underwent MRI of the knee joint at our institution to evaluate the role of T2 mapping sequence in assessment of the articular cartilage of the knee joint. Early degenerative changes and cartilage defects were successfully detected with T2 mapping sequence as shown in (Table 2).

Table (2): Summary of MR imaging parameters.

\begin{tabular}{|c|c|c|c|c|}
\hline Parameter & $\begin{array}{c}\text { Axial fat } \\
\text { saturated } \\
\text { T2 } \\
\text { weighted } \\
\text { FSE }\end{array}$ & $\begin{array}{c}\text { Coronal } \\
\text { fat } \\
\text { saturated } \\
\text { T2 } \\
\text { weighted } \\
\text { FSE }\end{array}$ & $\begin{array}{c}\text { Sagittal } \\
\text { fat } \\
\text { saturated } \\
\text { T2 } \\
\text { weighted } \\
\text { FSE }\end{array}$ & $\begin{array}{c}\text { Sagittal } \\
\text { T2 } \\
\text { mapping }\end{array}$ \\
\hline Repetition time & 4300 & 2000 & 5300 & 1500 \\
\hline Echo time & 77 & 20 & 22 & 27 \\
\hline Flip angle & 90 degree & 90 degree & 90 degree & 90 degree \\
\hline Field of view & $18 \mathrm{~cm}$ & $14 \mathrm{~cm}$ & $14 \mathrm{~cm}$ & $16 \mathrm{~cm}$ \\
\hline Section thickness & $3 \mathrm{~mm}$ & $2 \mathrm{~mm}$ & $2 \mathrm{~mm}$ & $3 \mathrm{~mm}$ \\
\hline Imaging time & $10 \mathrm{~min}$. & $10 \mathrm{~min}$. & $10 \mathrm{~min}$. & $15 \mathrm{~min}$. \\
\hline
\end{tabular}

In this study, all lesions detected on routine MRI of the knee, were diagnosed by T2 mapping, the T2 lesions appeared wider and some T2 lesions were not obvious on the routine MRI of the knee, and thus T2 mapping is helpful in detecting the cartilage lesions not obvious in routine MRI of the knee as shown in (Tables 3,4).

Table (3): Sensitivity and specificity of MRI protocol with T2 maps according to the articular surface.

\begin{tabular}{lcc}
\hline Articular surface & $\begin{array}{c}\text { Sensitivity } \\
(\%)\end{array}$ & $\begin{array}{c}\text { Specificity } \\
(\%)\end{array}$ \\
\hline Patella & 98 & 82 \\
Medial condyle of femur & 91 & 94 \\
Lateral condyle of femur & 84 & 95 \\
Medial plateau of tibia & 82 & 97 \\
Lateral plateau of tibia & 81 & 93 \\
\hline
\end{tabular}


Table (4): Sensitivity and specificity of MRI protocol with T2 maps according to arthroscopic grade.

\begin{tabular}{lcc}
\hline Arthroscopic grade & $\begin{array}{c}\text { Sensitivity } \\
(\%)\end{array}$ & $\begin{array}{c}\text { Specificity } \\
(\%)\end{array}$ \\
\hline 0 & 62 & 93 \\
1A & 68 & 91 \\
1B & 90 & 82 \\
$2 \mathrm{~A}$ & 92 & 81 \\
2B & 97 & 87 \\
3 & 100 & 88 \\
\hline
\end{tabular}

T2 mapping showed important changes in the cartilage below the defects. T2 mapping is helpful in determining the accurate lesion size especially in cartilage repair operations. No need for any special preparation or intravenous contrast in $\mathrm{T} 2$ mapping examination.

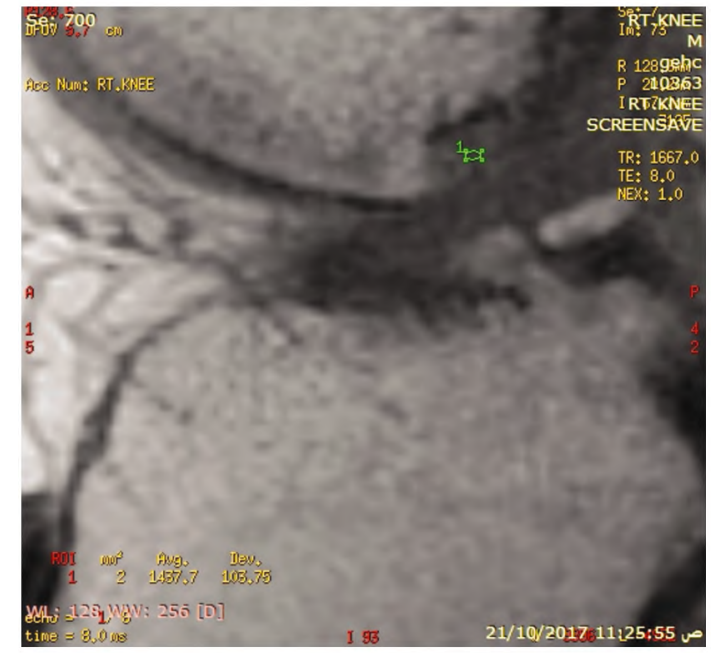

(A)

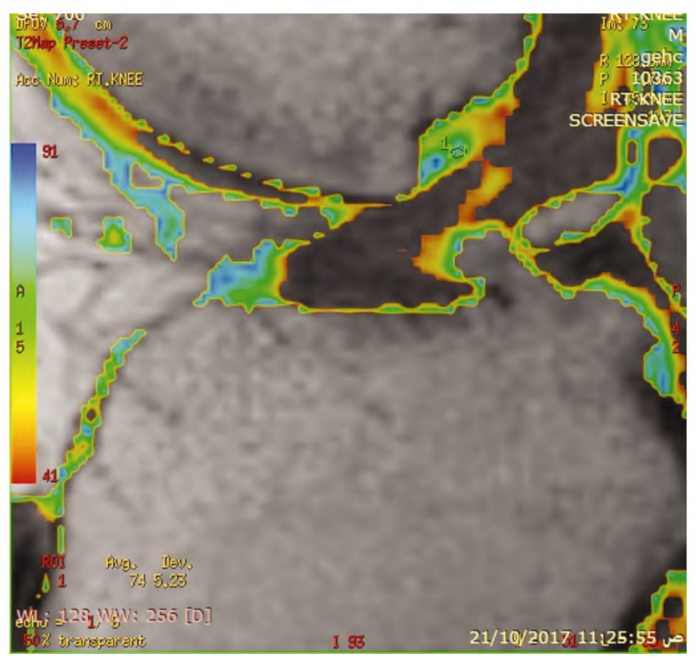

(C)
T2 mapping imaging was obtained at 1.5 tesla machine and T2 maps were estimated. The T2 relaxation time mapping within 5 minutes in one plane makes it reasonable and useful addition to the routine MRI of the knee. Therefore, T2 mapping images added useful information on cartilage lesions which seen in routine MRI of the knee and may determine the accurate nature of the cartilage lesion.

T2 mapping is extremely useful in the assessment of cartilage functional potential and can be used as a non-invasive technique to study the cartilage morphology of the cartilage tissue. Cartilage T2 mapping of knee joint may give new information that help in improving understanding osteoarthritis pathophysiology as shown in Figs. (1-5).

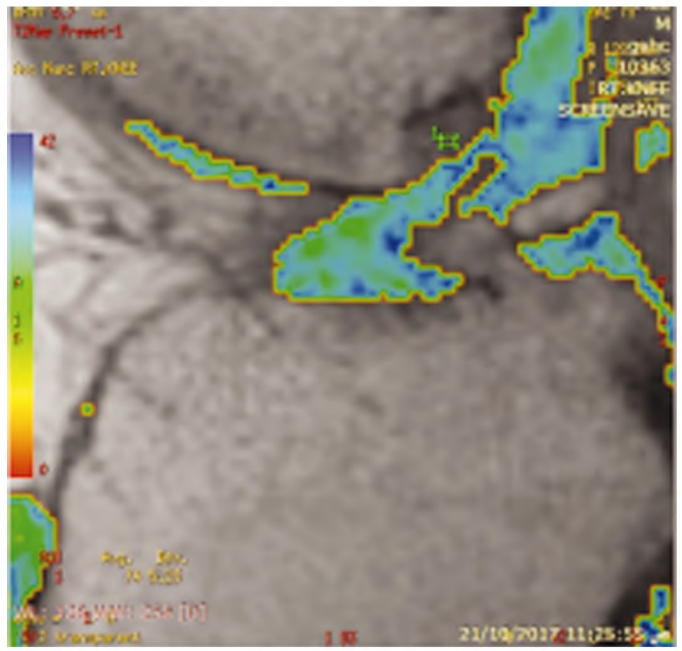

(B)

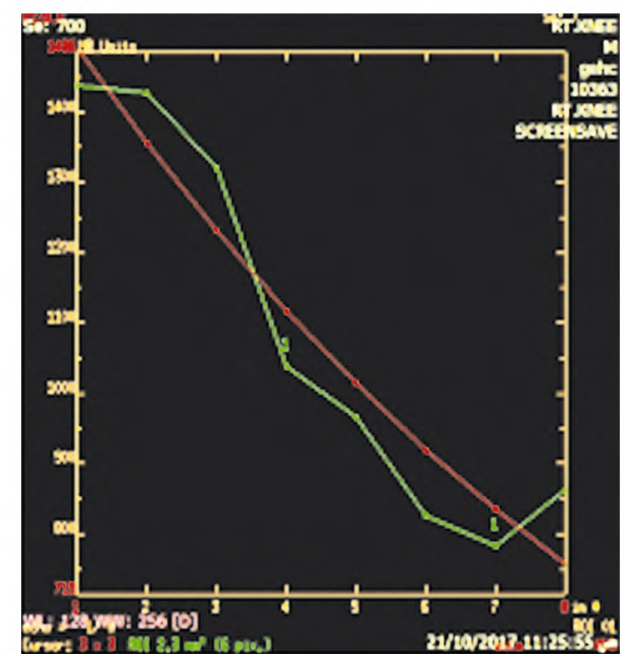

(D)

Fig. (1): Male patient 45 year-old with knee pain showing cartilage defect at the postero-lateral aspect of lateral femoral condyle with surface area of the defect measured about $30 \mathrm{~cm}^{3}$ (A). T2 mapping curve confirmed by color mapping showed T2 relaxation time measured $74 \mathrm{~m} \mathrm{sec}$ matching with early grade III cartilaginous lesion (B, C) the associated histogram curve showing drop of the curve at the site of defect in comparison to normal (D). 

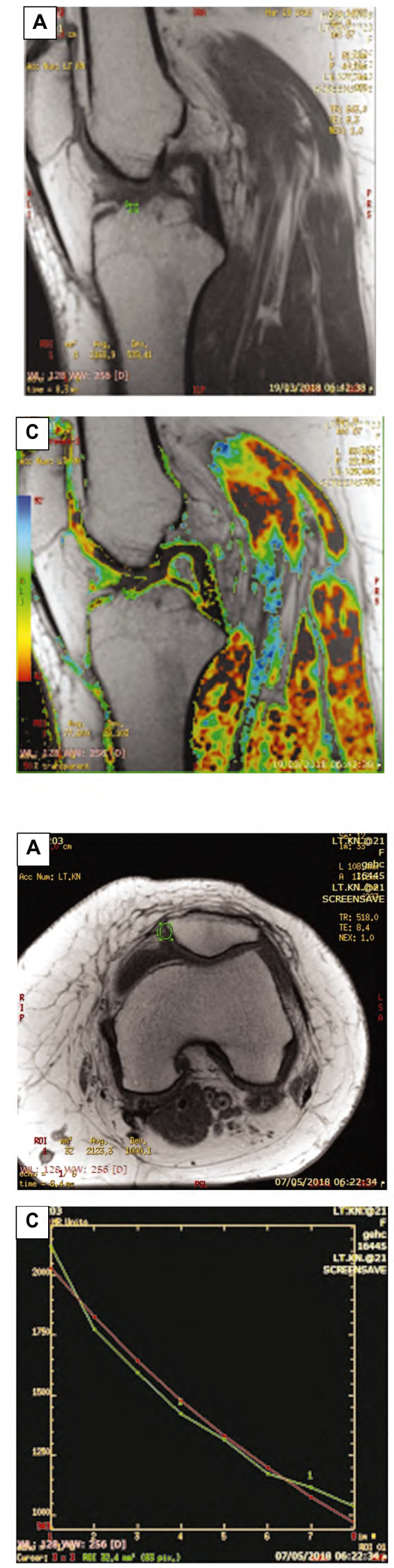
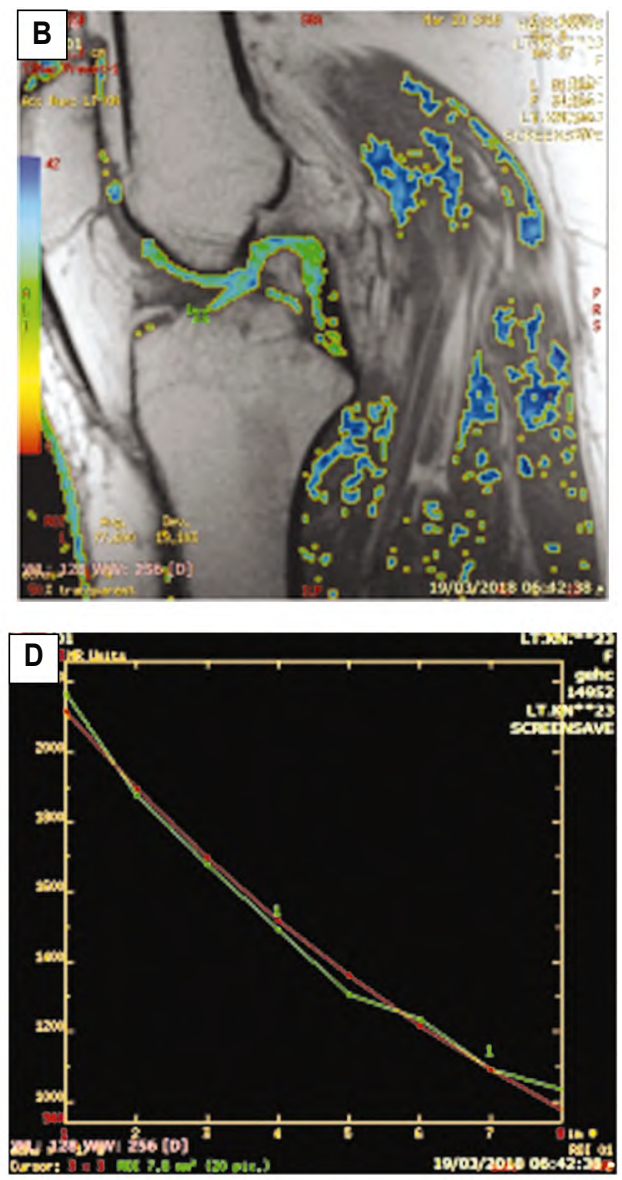

B
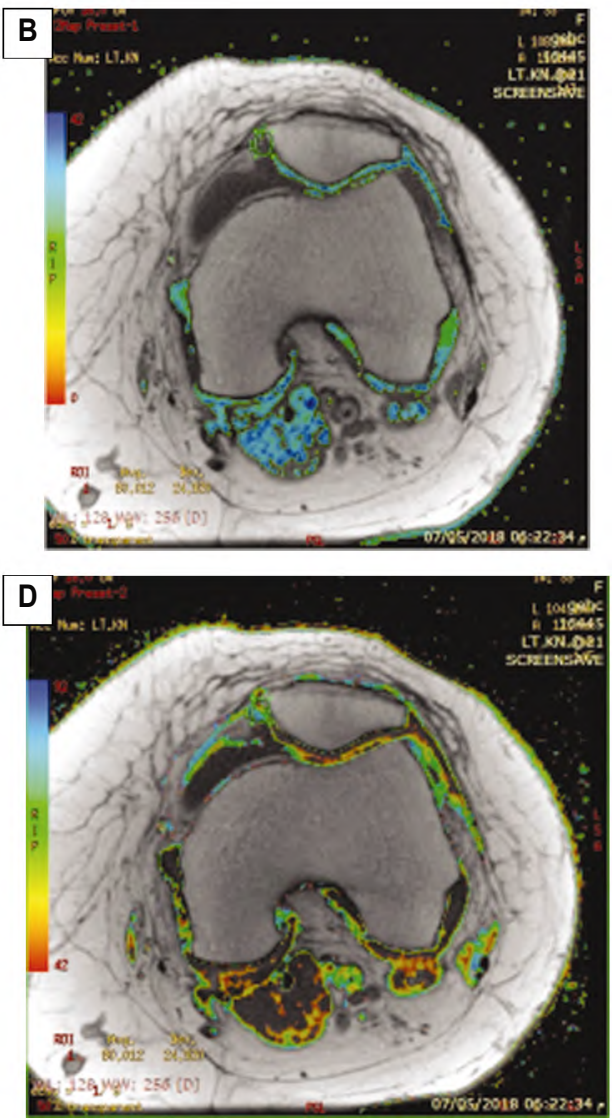

Fig. (2): Female patient 49 year-old with knee pain showing cartilage defect at the antero-lateral aspect of lateral tibial condyle with surface area of the defect measured about $15 \mathrm{~cm}^{3}$ (A). T2 mapping curve confirmed by color mapping showed T2 relaxation time measured $54 \mathrm{~m}$ sec matching with grade II cartilaginous lesion $(\mathrm{B}, \mathrm{C})$ the associated histogram curve showing drop of the curve at the site of defect in comparison to normal (D).
Fig. (3): Male patient 55 year-old with knee pain showing cartilage defect at the medial aspect of patellar cartilage with surface area of the defect measured about $10 \mathrm{~cm}$ (A). T2 mapping curve confirmed by color mapping showed $\mathrm{T} 2$ relaxation time measured $24 \mathrm{~m}$ sec matching with grade I cartilaginous lesion $(\mathrm{B}, \mathrm{C})$ the associated histogram curve showing drop of the curve at the site of defect in comparison to normal (D). 


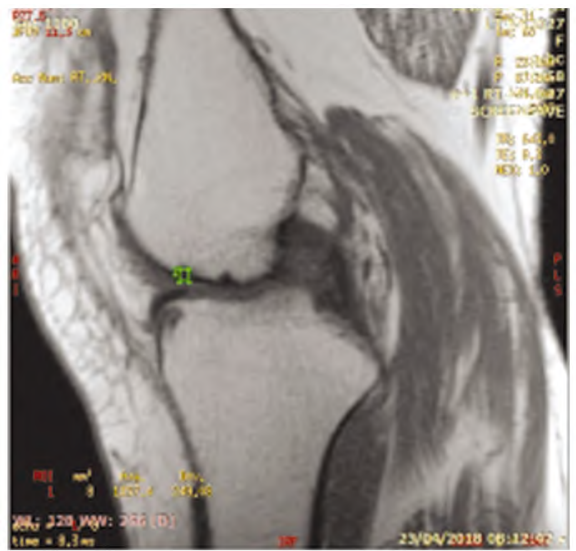

(A)

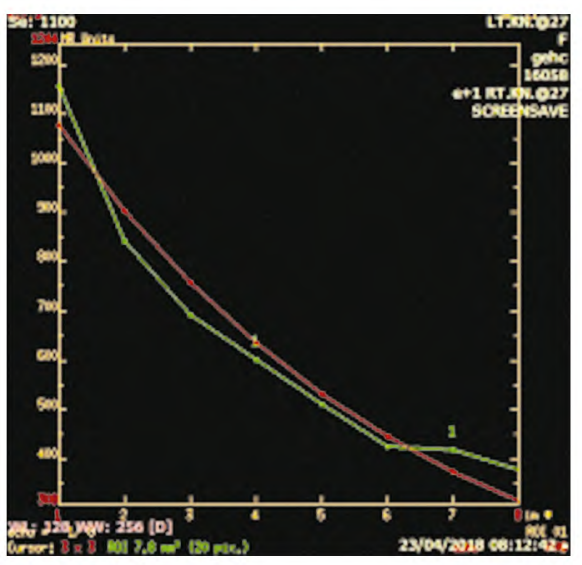

(C)

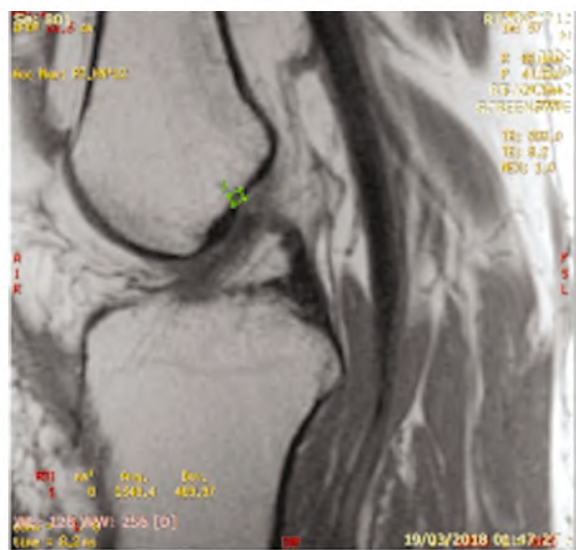

(A)

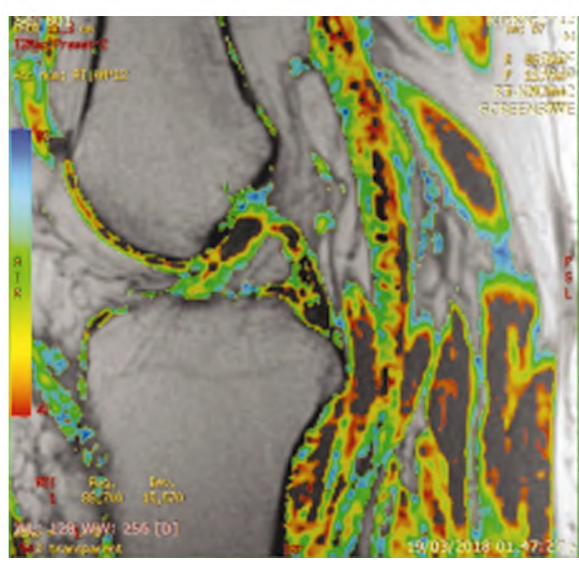

(C)

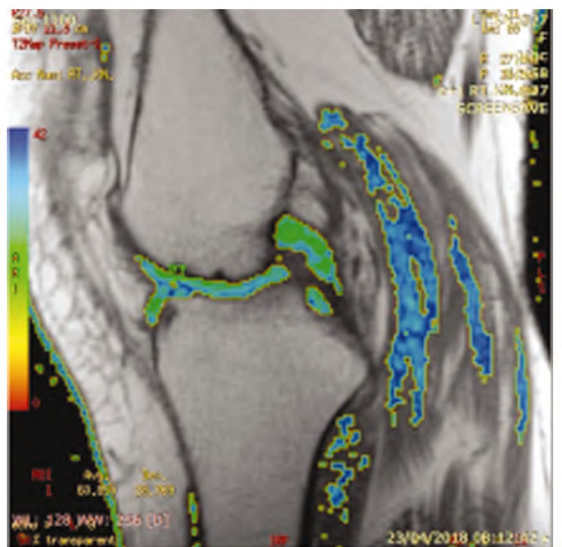

(B)

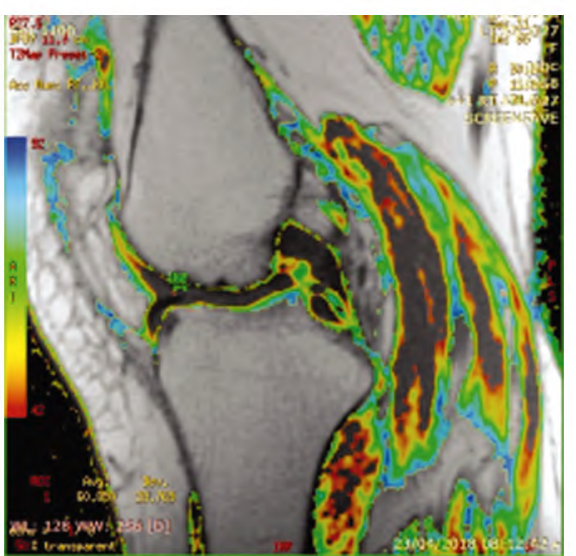

(D)

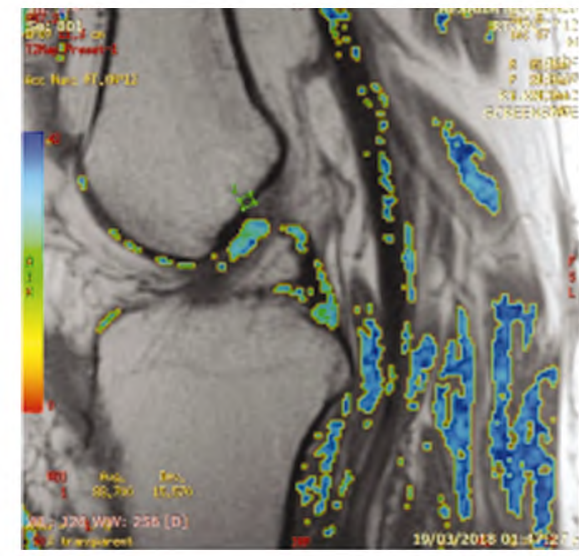

(B)

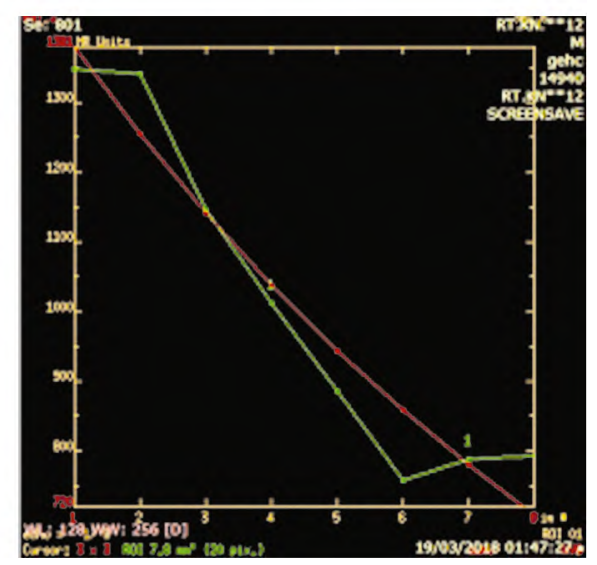

(D)
Fig. (4): Female patient 63 year-old with knee pain showing cartilage defect at the antero-medial aspect of medial femoral condyle with surface area of the defect measured about $12 \mathrm{~cm}^{3}$ (A). T2 mapping curve confirmed by color mapping showed $\mathrm{T} 2$ relaxation time measured $34 \mathrm{~m} \mathrm{sec}$ matching with grade I cartilaginous lesion $(\mathrm{B}, \mathrm{C})$ the associated histogram curve showing drop of the curve at the site of defect in comparison to normal (D).

Fig. (5): Male patient 65 yearold with knee pain showing cartilage defect at the postero-lateral aspect of medial femoral condyle with surface area of the defect measured about $20 \mathrm{~cm}^{3}$ (A). T2 mapping curve confirmed by color mapping showed $\mathrm{T} 2$ relaxation time measured $56 \mathrm{~m} \mathrm{sec}$ matching with grade II cartilaginous lesion (B, C) the associated histogram curve showing drop of the curve at the site of defect in comparison to normal (D). 


\section{Discussion}

Early osteoarthritic changes induce changes of the collagen network within the cartilage, and thus leading to increased water mobility and water content. Cartilage T2 relaxation time measurements reflect these pathophysiological changes [12-14].

$\mathrm{T} 2$ relaxation time was increased in cartilage degeneration due to increased water content and collagen matrix disruption $[\mathbf{1 5 , 1 6}]$. The increased $\mathrm{T} 2$ relaxation time was detected as areas of high signal intensity within the articular cartilage on T2-weighted images [17].

In this study, the addition of T2 mapping sequence to routine MRI of the knee significantly increased the sensitivity for detecting cartilage lesions within the knee joint, with improved detection of early cartilage degeneration. The low sensitivity for detecting early cartilage degeneration by using the the routine MRI of the knee was $62 \%$ and this was similar to the findings of Kijowski et al., Liess et al., and Goodwin et al., [18-20] which had reported the sensitivity for detecting cartilage lesion and cartilage defects ranging from $9 \%$ to $62 \%$ at both $1.5 \mathrm{~T}$ and $3.0 \mathrm{~T}$.

In this study we found that nine cases of increased T2 relaxation time corresponded to normalappearing cartilage in routine MRI of knee, and this in agreement with Hannila et al., [21] who evaluating patellar cartilage in 20 patients and found that eight areas of increased $\mathrm{T} 2$ relaxation time corresponded to normal-appearing cartilage in routine knee MRI. Apprich et al., [22] compared the articular cartilage of the medial femoral condyle in 43 patients by using T2 mapping sequence and routine MRI and found a significant association between the $\mathrm{T} 2$ relaxation time and the morphologic grade of the cartilage lesion.

\section{Conclusion:}

In conclusion, when T2 mapping sequence was added to the routine MRI of the knee the sensitivity for detecting knee cartilage lesions was increased, especially in the detection of early cartilage degeneration.

\section{References}

1- XIA Y., MOODY J.B., BURTON-WURSTER N., et al.: Quantitative in situ correlation between microscopic MRI and polarized light microscopy studies of articular cartilage. Osteoarthritis. Cartilage, 9: 393-406, 2001.

2- SMITH H.E., MOSHER T.J., DARDZINSKI B.J., et al.: Spatial variation in cartilage T2 of the knee. J. Magn. Reson. Imaging, 14: 50-5, 2001.
3- MLYNÁRIK V.: Magic angle effect in articular cartilage. AJR, 178: 1287, 2002.

4- GOODWIN D.W. and DUNN J.F.: MR imaging and T2 mapping of femoral cartilage. AJR, 178: 1568-9, 2002.

5- BOEGARD T., RUDLING O., PETERSSON I.F., et al.: Correlation between radiographically diagnosed osteophytes and magnetic resonance detected cartilage defects in the tibiofemoral joint. Ann. Rheum. Dis., 57: 401-7, 1998.

6- COUMAS J.M. and PALMER W.E.: Knee arthrography: Evolution and current status. Radiol. Clin. North Am., 36: 703-28, 1998.

7- GOLD G.E., HARGREAVES B.A., REEDER S.B., et al.: Controversies in protocol selection in the imaging of articular cartilage. Semin. Musculoskelet. Radiol., 9: 16172, 2005.

8- GOLD G.E., HARGREAVES B.A., STEVENS K.J., et al.: Advanced magnetic resonance imaging of articular cartilage. Orthop. Clin. North Am., 37: 331-47, 2006.

9- KIJOWSKI R., BLANKENBAKER D.G., KLAERS J.L., et al.: Vastly undersampled isotropic projection steadystate free precession imaging of the knee: Diagnostic performance compared with conventional MR. Radiology, 251 (1): 185-94, 2009.

10- KIJOWSKI R., BLANKENBAKER D.G., DAVIS K.W., et al.: Comparison of 1.5-and 3.0-T MR imaging for evaluating the articular cartilage of the knee joint. Radiology, 250 (3): 839-48, 2009.

11- KIJOWSKI R., BLANKENBAKER D.G., WOODS M.A., et al.: 3.0-T evaluation of knee cartilage by using threedimensional IDEAL GRASS imaging: Comparison with fast spin-echo imaging. Radiology, 255 (1): 117-27, 2010.

12- ROEMER F.W., CREMA M.D., TRATTNIG S., et al.: Advances in imaging of osteoarthritis and cartilage. Radiology, 216: 332-54, 2011.

13- CREMA M.D., ROEMER F.W., MARRA M.D., et al.: Articular cartilage in the knee: Current MR imaging techniques and application in clinical practice and research. Radiographics, 31: 37-61, 2011.

14-ECKSTEIN F. and WIRTH WAND NEVITT M.C.: Recent advances in osteoarthritis imaging-the osteoarthritis initiative. Nat. Rev. Rheumatol., 8: 622-30, 2012.

15- DUNN T.C., LU Y., JIN H., et al.: T2 relaxation time of cartilage at MR imaging: Comparison with severity of knee osteoarthritis. Radiology, 232 (2): 592-8, 2004.

16- REGATTE R.R., AKELLA S.V., LONNER J.H., et al.: T1rho relaxation mapping in human osteoarthritis (OA) cartilage: Comparison of T 1rho with T2. J. Magn. Reson. Imaging, 23 (4): 547-53, 2006.

17- MOSHER T.J., DARDZINSKI B.J. and SMITH M.B.: Human articular cartilage: Influence of aging and early symptomatic degeneration on the spatial variation of T2preliminary findings at 3T. Radiology, 214 (1): 259-66, 2000.

18- KIJOWSKI R., BLANKENBAKER D.G., WOODS M.A., et al.: 3.0-T evaluation of knee cartilage by using threedimensional IDEAL GRASS imaging: Comparison with fast spin-echo imaging. Radiology, 255 (1): 117-27, 2010 
19- LIESS C., LÜSSE S., KARGER N., et al.: Detection of changes in cartilage water content using MRI T2-mapping in vivo. Osteoarthritis Cartilage, 10 (12): 907-13, 2002.

20- GOODWIN D.W., WADGHIRI Y.Z., ZHU H., et al.: Macroscopic structure of articular cartilage of the tibial plateau: Influence of a characteristic matrix architecture on MRI appearance. A.J.R., 182 (2): 311-8, 2004.

21- HANNILA I., NIEMINEN M.T., RAUVALA E., et al.:
Patellar cartilage lesions: Comparison of magnetic resonance imaging and $\mathrm{T} 2$ relaxation-time mapping. Acta Radiol., 48 (4): 444-8, 2007.

22- APPRICH S., WELSCH G.H., MAMISCH T.C., et al.: Detection of degenerative cartilage disease: Comparison of high-resolution morphological MR and quantitative T2 mapping at 3.0 Tesla. Osteoarthritis Cartilage, 18 (9): 1211-7, 2010

\section{رسهم الخرائط بإستخدام وقت الإسترخاء

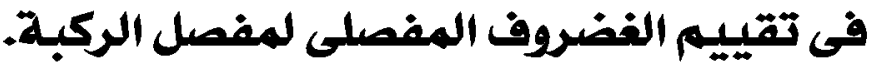

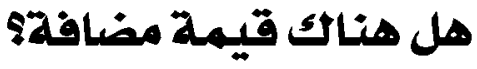

الخلفية: إن تشخيص الإنحطاط المبكر فى غضروف الركبة فى المرضى الذين خضعوا لتصوير الرنين المغناطيسى الروتينى له آهمية

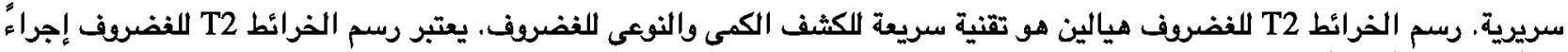
كمياً يوفر رسيماً ملوناً بالمعلومات والكشف الكمي للفضاريف مثل التثكل وتوزيع الهياه وحجم آلياف الكولاجين.

الهدف من هذه الدراسلة: هو تقييم قيمة إضافة تسلسل رسم الخرائط T2 إلى التصوير بالرنين المفناطيسى الروتينى اللركبة لتقييم الفضروف المفصلي لمفصل الركبة.

النتائج: فى هذه الدراسة وجدنا أن تسع حالات زيادة وقت الإسترخاء T2 المقابلة للفضروف الظاهر العادى تشخيصها بواسطة التصوير

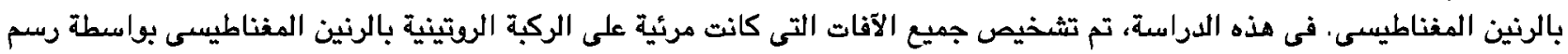

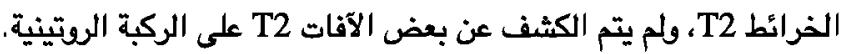

الخلاصدة: عندما تمت إضافة تسلسل رسم الخرائط T2 إلى التصوير بالرنين المغناطيسى الروتينى للركبة، زادت حساسية للكشف عن

آفات غضرفف الركبة، وخاصة فى الكثف عن تتكس الغضاريف المبكر. 